\title{
Figures et expériences diasporiques
}

\section{Abdoulaye Gueye}

\section{(2) OpenEdition}

\section{Journals}

Édition électronique

URL : https://journals.openedition.org/remi/2711

DOI : $10.4000 /$ remi. 2711

ISSN : $1777-5418$

Éditeur

Université de Poitiers

Édition imprimée

Date de publication : 1 mars 2006

Pagination : 7-9

ISBN : 2-911627-41-5

ISSN : 0765-0752

Référence électronique

Abdoulaye Gueye, "Figures et expériences diasporiques », Revue européenne des migrations internationales [En ligne], vol. 22 - $n^{\circ} 1 \mid$ | 2006, mis en ligne le 27 novembre 2008, consulté le 14 avril 2022. URL : http://journals.openedition.org/remi/2711 ; DOI : https://doi.org/10.4000/remi.2711

Ce document a été généré automatiquement le 14 avril 2022

(C) Université de Poitiers 


\title{
Figures et expériences diasporiques
}

\author{
Abdoulaye Gueye
}

1 La littérature en sciences sociales témoigne d'un intérêt tangible pour la réflexion sur la diaspora ces dernières années. Dans la recherche anglo-américaine notamment et aussi dans la littérature francophone un nombre important de chercheurs ont investi cette thématique. À bien des égards, cette dynamique de recherche ne peut être soupçonnée d'être en décalage avec l'évolution actuelle de nos sociétés. Tout au contraire. La période en question est celle de mutations profondes consistant entre autres en l'affaiblissement - non pas la disparition - de l'État-nation, l'irruption en force dans l'espace public des identités particularistes auxquelles nombre d'États aménagent un espace d'expression et l'accroissement des flux transnationaux. Ainsi la plupart des sociétés contemporaines sont devenues des sociétés ethniquement hétérogènes abritant aux côtés de citoyens se définissant comme autochtones des populations allochtones qui se soucient d'exprimer leurs différences d'autant qu'elles subissent une discrimination et un rejet de la part de la majorité autochtone.

2 Par cette conscience d'être dépositaires d'une culture autre, de se confronter à une discrimination et de vivre en situation de minorité dans un pays qu'on leur refuse ou qu'ils hésitent parfois à considérer comme leur patrie d'origine, ces populations allochtones tissent des réseaux de solidarité avec leur foyer d'origine et cultivent l'espoir de la réhabilitation de leur communauté et le retour fantasmé ou planifié au pays d'origine. Ainsi, deviennent-elles les sujets d'au moins une double allégeance nationale: d'une part, elles sont amenées à se préoccuper du destin de leur pays d'installation, par patriotisme ou par la force de la loi, d'autre part, elles s'investissent dans le futur d'une société d'origine par ressentiment ou affection identitaire. Ce faisant, elles visent à se constituer comme diaspora.

3 Le présent dossier rassemble des articles qui analysent le processus de construction de cette identité diasporique, à partir de contextes géographiques et de sujets d'étude différents. Leurs auteurs se rejoignent sur deux points importants. D'abord, ils adoptent tous une approche constructiviste de la diaspora. Ensuite, ils se penchent sur des figures et expériences de diasporas qui ne sont pas les exemples classiques de la diaspora grecque, juive et arménienne. L'article d'Abdoulaye Gueye porte sur la 
diaspora noire. En préambule, l'auteur se préoccupe d'établir les mécanismes institutionnels ainsi que les facteurs sociaux de production d'une diaspora noire en France. Il adopte, pour ce faire, une approche socio-historique qui éclaire les origines coloniales de la naissance de cette diaspora et met en évidence les ruptures et continuités dans la construction de celle-ci. Dans la partie centrale de son article, Gueye identifie les fondements épistémologiques de l'absence de recherche sur la diaspora noire dans les sciences sociales françaises. Il montre comment la structuration des sciences sociales françaises et le rapport de dépendance dans lequel s'installent ces sciences avec le pouvoir politique freinent l'investissement de ce champ de réflexion par les chercheurs français.

4 S'inscrivant dans une même approche critique que le précédent, Mickaella Périna se penche sur le cas des populations noires des Antilles françaises. Dans une démarche philosophique et historique, elle montre comment l'identité diasporique se construit dans un face-à-face entre un Soi et un Autre dans le regard duquel le premier prend la mesure de toute son identité. Les Noirs antillais tardivement intégrés dans la nation française à la suite de l'abolition de l'esclavage en 1848 se verront confinées au départ dans une altérité africaine par une population de colons béké, français par juis sanguinis, qui leur rappellent sans cesse qu'ils sont des Français seulement par décret. Par ce rappel, les Noirs antillais sont informés de la prévalence du sang comme critère d'appartenance nationale. De cette frontière, entre eux et les Français par le sang va se nourrir la double posture des Noirs antillais qui se considèrent comme membre de la nation française, d'une part, et réfèrent toujours à un foyer d'origine qui n'est pas la France, d'autre part.

L'article de Bettina Conrad analyse les mécanismes et le processus de fabrication de la diaspora érythréenne d'Allemagne. Bien qu'elle ne soit pas une diaspora classique comme la grecque ou la juive, la diaspora érythréenne en épouse presque toutes les caractéristiques. Elle a résulté de l'exil d'un peuple dont le territoire était occupé par les forces étrangères (celles de l'Éthiopie) contre lesquelles ses leaders nationalistes vont mener pendant près de trente ans une guerre qui se soldera par une déclaration d'indépendance. De leur exil allemand, les Érythréens se mobilisent en réseaux pour pourvoir les armées érythréennes des ressources nécessaires à la conquête de l'indépendance et alimentent le projet d'un retour imminent qui justifiait l'éducation des enfants nés ou élevés en Allemagne suivant les valeurs et principes de la société d'origine. Conrad montre cependant comment ce nationalisme à distance s'avérera, pour cette génération née ou élevée en Allemagne, impuissante à combler le fossé qui la sépare de leurs "compatriotes" restés en Érythrée lorsqu'elle aura à accomplir le "pèlerinage" tant attendu au pays natal. En fait, les jeunes restés en Érythrée sont porteurs d'une culture de guerre qui s'opposent complètement à la culture d'exil de leurs "compatriotes" en provenance de l'Allemagne. Dans ce face-à-face avec leurs congénères d'Érythrée, se dévoile la complexité de leur identité culturelle dont ils réalisent qu'elle n'est pas entièrement érythréenne, mais composite, en partie érythréenne, en partie allemande.

Dans son article qui clôt ce dossier, Scott Simon nous révèle à la complexité de la question identitaire dans la société taiwanaise. Comme celui de Conrad, l'article de Simon met en lumière la contribution de la violence dans la fabrication d'une identité diasporique. Taiwan qui constitue son terrain d'observation est une société ayant connu plusieurs occupations étrangères. Par conséquent, elle abrite une population qui 
revendique le statut de primo-arrivant, en même temps qu'elle compte des citoyens venus de Chine, sous l'occupation chinoise de cette île pour les uns, et après le retrait des troupes nationalistes de Chiang Kai-shek à la suite de la victoire des communistes de Mao, pour les autres. Simon montre que, dès leur contrôle de cette île, les Chinois du continent ont joui d'un statut privilégié, occupant les positions administratives les plus élevées et rejetant aux marges de la société les autres groupes dont ils avaient dévalorisé par surcroît les cultures. Cette inégalité contribuera à l'édification de frontières ethniques entre ces populations, en particulier les Chinois du continent et les natifs Taiwanais qui à bien des égards ne se distinguent pas les uns des autres. La décolonisation officielle de l'île de Taiwan et l'accès des autochtones et des natifs Taiwanais au pouvoir politique avec l'élection de l'un des leurs à la tête du pays a fini de constituer une diaspora chinoise de Taiwan. Les ressortissants de la Chine continentale développent ainsi le sentiment d'être des étrangers dans leur société de naissance qu'ils dominaient et qui leur apparaissait auparavant comme une extension de la Chine continentale. Ainsi, se retrouvent-ils écartelés entre le sentiment d'être chinois et celui d'être taiwanais.

\section{AUTEUR}

\section{ABDOULAYE GUEYE}

University of Ottawa, Department of sociology, 550 Cumberland, Ottawa, On. Canada K1N 6N5 